\title{
Hybridity and the Quest for Identity in Tayeb Salih's Season of Migration to the North (1969)
}

\author{
By Lahcen Ait Idir*
}

\begin{abstract}
The construction of "otherness" in postcolonial literature is ostensible in Tayeb Salih's Season of Migration to the North. Salih's narrative, by means of a device of reversal, renarrates Joseph Conrad's Heart of Darkness in such a way that it challenges the ideological claims of empire embedded in it. Such concept of Otherness seems to entail unity and purity of the two entities of Self and Other as they are ascribed two clear-cut types of qualities that draw a neat-division between them, and deny any influence that one might have on the other, namely in moments and spaces of encounter and negotiation. Yet, during and after colonial and cultural encounters and migratory processes that the world has experienced, such concept of Other/Otherness is conceived of as being erroneous; for identities, a complex concept indeed, have been in a perpetual flux to the point that hybridity is the dominant trait of colonial and postcolonial subjects. In this line of thought, hybridity tends to debunk the system of binarism which is mistakenly deployed in the representation of "selves" and "others". Such binarism is, however, drawn into a Lacanian mirror-image wherein the identity of Self/Other is complementary; for only in encountering the Other does the Self know itself. This paper intends to examine the manifestations of hybridity along with the question of the Self's quest for identity in Season of Migration to the North. In the light of the different thoughts that have informed the concept of hybridity, the paper also looks at signs of ambivalence and mimicry in the work of Tayeb Salih.
\end{abstract}

Keywords: Ambivalence, Hybridity, Identity, Mimicry, Otherness, Postcolonialism, Tayeb Salih

\section{Season of Migration to the North: African Man and Identity Alteration}

Tayeb Salih and Joseph Conrad use literary writing to discuss a wide range of issues that have emerged from colonial history and cultural encounters. Heart of Darkness and Season of Migration to the North offer, in their varying ways, perspectives on the hybrid identities and the predicament of the traumatized "mixed-race" or "in-between-groups" originally belonging to one country and living in "exile". Characters are trapped between two spaces and cultures. Displaced, marginalized and alienated in pain-infused and exotic spaces, these characters have developed, in different ways, hybrid identities, ambivalent attitudes, and mimic acts. This is visible in Salih's Season of Migration to the North. The latter, along with similar works such as V.S Naipaul's The Mimic Men, remains one of the fascinating works that offer an interesting perspective on postcolonial subjects who clearly demonstrate hybrid identities, ambivalent visions and attitudes as well as mimic aspects. These ideas can be said to have stark reflection in Salih's unnamed narrator and the focal character of Mustapha Sa'eed.

There is evidence that the hybrid and fragmented identities of Salih's characters are the outcome of center periphery encounter. Enduring a sense of dislocation, the unnamed narrator and Mustapha find themselves marginalized by community and placed in an in-between space of cultural hybridity. In no manner,

* Doctoral Candidate, Sultan Moulay Slimane University, Morocco. 
the hybridizing process has turned characters into strangers and alienated people; be they in the English metropolis or in their own homes, particularly after their return to Africa. On this basis, this section investigates the aspects of cultural hybridity in Salih's narrative through the lens of Homi K. Bhabha's theorization of concepts like "hybridity", "mimicry", "ambivalence" and "in-betweenness". In doing so, it will be clear that Salih's ambivalent text opens a space wherein the borders between self and other are effaced, and wherein hybridity remains the distinctive feature of the identity of the (post)colonial subjects, hence "rejecting cultural paradigms of purity, singularity, and alterity" (Geesey 1997: 130). In this way, Salih's narrative will be dissected as it sets out to go beyond the classical view of identity. Deconstructed on the basis of postmodern and postcolonial thought, the essentialist mode of thinking about identity proves to be mistaken, for identities are in a perpetual flux, and the contact between self and other is always in a case of becoming.

\section{Dislocation and Hybrid Identities}

Perhaps the paramount point of entry to the examination of aspects of cultural hybridity in Season of Migration to the North is to give some biographical notes on the unnamed narrator and Mustapha Sa'eed who are good instances of hybrid characters. First, Mustapha spends most of his life dislocated and without a fixed abode; he is born in Sudan wherein he gets his preliminary education in the colonial school, and then he moves to Egypt and has his first contact with the European Man. Having spent some time in Egypt, Mustapha then moves to England wherein he gets his $\mathrm{PhD}$ and teaches economics at Oxford University. It is also in England that Mustapha has immense contact with European culture, and wherein he "got to know the pubs of Chelsea, the clubs of Hampstead, and the gatherings of Bloomsbury. [And he] would read poetry, talk of religion and philosophy, discuss paintings" (Salih 1969: 29-30). Nicknamed the "black Englishman" (Salih 1969: 52), a significant name that is revelatory of his hybrid identity, "Mustafa Sa'eed was the first Sudanese to marry an English woman, in fact he was the first to marry a European of any kind... he took himself off abroad long ago. He married in England and took British nationality" (Salih 1969: 55-56). Certainly, Mustapha's dislocation in England and his extensive contacts with white women have made of him a man of two identities and cultures. All of these facts provide legitimacy to assume the cultural hybridity of Mustapha who belongs nowhere; for he is of an Arab-African origin and lives in the metropolitan center by whose culture Mustapha becomes highly influenced. It is in this sense that Mustapha loses his native identity and embraces multiple identities. Yet, as it shall be made clear later, Mustapha's hybrid identity results in his enduring a traumatic experience and self-dividedness, notably after his return to his native village, in a way reminiscent of Conrad's Kurtz in Heart of Darkness wherein the white man's homelessness and his being trapped between two cultures have led to his loss of self, and his tragic death. 
Similar to Mustapha, the unnamed narrator's identity is culturally hybrid. Displaced in England, the unnamed narrator is a Sudanese man who returns to his people in Africa after seven years of stay and study in England wherein he gets a $\mathrm{PhD}$ in English poetry. The unnamed narrator's sojourn and education in the west is suggestive of the western cultural influence on him and on his native identity. On this basis, the unnamed narrator, a product of two experiences and cultures, remains a good example of cultural hybridity in Season of Migration to the North. Yet, although the unnamed narrator "has been similarly affected by the cultural 'contact' between England and the Sudan, [he] is at first unwilling to acknowledge this reality" (Geesey 1997: 129). In fact, Salih's narrative teems with many instances that account for the unnamed narrator's rejection of his cultural hybridity and his insistence on his and his own people's purity. One of the passages that hint at this idea of the narrator's denial of his cultural hybridity reads as follows:

I heard the cooing of the turtle-dove, and I looked through the window at the palm tree standing in the courtyard of our house and I knew that all was still well with life. I looked at its strong straight trunk, at its roots that strike down into the ground, at the green branches hanging down loosely over its top, and I experienced a feeling of assurance. I felt not like a storm-swept feather but like that palm tree, a being with a background, with roots, with a purpose. (Salih 1969: 2) [Emphasis mine]

Evidently, the narrator appears to refuse his hybridity or any cultural effect of Europe on him during his stay in England. This idea finds expression in the comparison which the narrator draws between the "palm tree" and his "sense of self". More than this, the narrator strives hard to confirm that he has a cultural background and a belonging, and that he is not uprooted. To further evince his sense of belonging to his native village, "the narrator first takes his fixed role in the village of his ancestors, namely his grandfather's, for granted" (Stampfl 2009: 170). Yet, such sense of belonging and attempts to reintegrate in his "pays natal" are disturbed after his encounter with the colonial culture of the Europeans. It is at this juncture that the narrator comes to realize his hybrid identity, notably after his digging into Mustapha's life story as Geesey clearly states:

The narrator too has been similarly affected by cultural "contact" between England and the Sudan, but he is at first unwilling to acknowledge this reality. Only through his exploration of Mustafa Sa'eed's account of his life does the narrator come to understand more fully the nature of cultural contact and contamination between Sudan and its former colonial power. (Geesey 1997: 129)

Geesey's notes remain important for they unveil the narrator's hybrid identity. In fact, the narrator's attempt to hide his hybridity is of no avail, especially after his "exploration of Mustapha's account", and his encounter with him. It is at this moment that the narrator realizes his cultural hybridity as he is a product of two experiences and cultures between which he is "trapped". In one of the narrator's meetings with Mustapha, the latter provides statements that go beyond the purity 
of cultures and identities in such a way that debunks the narrator's perception of identity as being fixed. Digging around a palm tree, Mustapha tells the narrator that "some of the branches of this tree produce lemons, others oranges" (Salih 1969: 15). Certainly, Mustapha's statement is very telling as it contains signs that reveal cultural hybridity. Similar to the tree which gives birth to two different types of fruits, Mustapha and the narrator belong to two spaces, cultures, and identities. More than this, Mustapha's statement challenges the western essentialist view of identities as being characterized by fixity and changelessness. Rather, identities, as the postcolonial thought has suggested, are fragmented; for "the experience of migration or of exile has become...emblematic of the fissured identities and hybridities generated by colonial dislocation" (Loomba 1998: 180). In this, Salih's characters' migration, exile, and dislocation, are all important factors that have provided a fertile environment for their development of fragmented and hybrid identities, hence the loss of pure identity and self. In keeping with the examples of Mustapha and the narrator, the occurrence of hybridity in their case has led to serious repercussions and conflicts within their "selves" to the point that they feel a sense of alienation, strangeness, and nonbelonging, all of these have resulted in their ongoing quest for identity and their tragic ends. These ideas will be dwelt on in details in the coming paragraphs that will deal with ambivalence, mimicry and quest for identity.

With regard to the cultural hybridity of Salih's characters, it is perhaps safe to assume that Hosna, Mustapha's native wife, is also culturally hybrid. The evidence for this idea resides in the fact that she seems to be influenced by Mustapha's western modern frame of mind in that she tries to rebel against the African traditions and the African patriarchal mode of thought. This idea can be extrapolated from her rebuff to the suggestion of Wad Rayyes's marriage. Yet, although, as the narrator informs Wad Rayyes, Hosna threateningly rejects any marriage after the death of her husband Mustapha, Wad Rayyes, who "burst [s] out into a crazy fit of rage" (Salih 1969: 97) expresses his anger at the narrator and he insists that "She'll marry me whatever you or she says or does. Her father's agreed and so have her brothers. This nonsense you learn at school won't wash with us here. In this village the men are guardians of the women" (Salih 1969: 98). Certainly, Wad Rayyes's statement is illustrative of the phallocentric domination of men in the post-independence Sudan society against which rebellion is exhibited on the part of "Hosna, Mustafa's wife, [who] had become in some measure westernized through contact with him" (Makdisi 1992: 819). Indeed, her murder of Wad Rayyes and her killing of herself can be read as an attempt to liberate the frame of thinking that she has acquired from Mustapha and whereby she supports women's struggle for their existence and against "the extreme side of traditionalism" (Makdisi 1992: 819) incarnated in the character of Wad Rayyes. Although she has never been dislocated or experienced any migratory movement, her acts can be interpreted as indexes of cultural hybridity. In the main, culturally hybrid, Salih's characters are representative of what Fanon has qualified as black skin/white masks; of African origin, Salih's characters adopt the western frame of mind in such a way that accounts for the fact that colonial identities are in a perpetual flux, particularly in the postcolonial world. This latter idea challenges 
the Manichean perception with regard to identities. Yet, characters' hybrid identities and the situation of being torn between two identities and worlds have led to their endurance of a traumatic and painful experience along with a psychological disturbance.

\section{Signs of Ambivalence in Season of Migration to the North}

There are perceptibly many issues that relate Season of Migration to the North to Heart of Darkness. Certainly, Conrad's Marlow constructs in different contexts and towards different characters unsure and ambivalent statements which are evocative of his perplexity, hence his, conscious or unconscious tendency to efface any borders built between the self/otherness on the basis of language, culture and civilization. More fascinating to note is the fact that his ambivalent attitudes are expressed not only towards Africans but also towards his white fellows, particularly in his quest for identity and his dark side reflected in the elusive character of Kurtz. Just like Conrad's narrative, Salih's narrative teems with enough statements that exhibit the African characters' "mixed feelings through the essential dichotomies marking the lives of émigrés...love-hate relationships, contradictions between 'self' and 'other' native-alien clash of cultures, hybridity...sense of alienation and ultimate disillusionment" (Kumar 2011: 1). In this sense, Salih's Mustapha and the narrator remain good examples of postcolonial subjects' ambivalent feelings and attitudes. Interesting to note is that ambivalence is clear in Salih's characters with regard to their relationships with one another and with the European wo/men. To illustrate, let's consider the following excerpt from the outset of the novel when the narrator is faced with a couple of questions by people of his native village upon his return from Europe. Parenthetically, the villagers' questions revolve around the idea whether Europeans are like them or different from them. The narrator's response reads as follows:

I told them [the villagers] that Europeans were, with minor differences, exactly like them, marrying and bringing up their children in accordance with principles and traditions, that they had good morals and were in general good people...just like us they are born and die, and in the journey from the cradle to the grave they dream dreams some of which come true and some of which are frustrated; that they fear the unknown, search for love and seek contentment in wife and child; that some are strong and some are weak... (Salih 1969: 3)

The passage above deconstructs and effaces borders of difference between Africans and Europeans. In this sense, the narrator's attitude springs from his growing awareness of the fact that the construction of the Otherness of different people, hence their exclusion from the community of "selves", is unfounded and is typical of essentialist thinking which has, in turn, proved to be devoid of any basis of validity. Certainly, the images of Africans and Europeans are represented as being almost the same but with slight differences. This is to underline the pluralistic feature of (post) colonial subjects, hence to 
go beyond the essentialist way of seeing identities as pure "selves" and pure "others". Salih's text thus rests on ambivalence and hybridity which refute the monolithic perception of identities, and underline the fact that the self's and other's identities are complementary. The argument here foregrounds the role that the other plays in defining the self. Hence, it is only in coming across the other does the self come to terms with itself as the Lacanian idea on the mirrorimage has underlined. Seen in this light, no less striking is, as the above passage evidences, the narrator's tendency to negotiate identity beyond the scope that the essentialist Manichean thought has drawn.

Following the same line of reasoning, important to note is the fact that Salih's text carries within it many elements that testify to its ambivalence, and its contradictory attitudes towards the white man. Passages that are accountable for this idea pervade the whole narrative. The subsequent extract can be seen as a good case in point wherein the narrator shows, in sheer contradistinction to Mustapha, indifference with regard to the European man and the British colonizer:

I too had lived with them. But I had lived with them superficially neither loving nor hating them....Over there is like here, neither better nor worse. But I am from here, just as the date palm standing in the courtyard of our house has grown in our house and not in anyone else's. The fact that they came to our land... Sooner or later they will leave our country just as many people throughout history left many countries. The railways, ships, hospitals, factories and schools will be ours and we'll speak their language without either a sense of guilt or a sense of gratitude. (Salih 1969: 49)

Once again, the narrator's attitude rests on both ambivalence and indifference. Striking is the narrator's tendency to efface walls of difference that are built between Europe and Africa. In fact, affinities between the two entities are highlighted and not disregarded. More than this, in contradiction to Mustapha who exhibits a profound impulse for exacting revenge on the white men for the harm they have done to Africa and Africans, the narrator, as the passage shows, holds an attitude which runs counter Mustapha's and in such a way that, as Shaheen states, weakens "the conflict of cross-culture between the Arab-African background of South and the new environment of the North" (Shaheen 1985: 163). Certainly, the narrator's above attitude with regard to the white colonizers is conspicuous in so far as the ambivalent feature of Salih's text is concerned. Salih's text carries within it elements that either express ambivalence. In keeping with this very question, the narrator's statement that "we will speak their [the white man's] language without either a sense of guilt or a sense of gratitude" remains very telling. Indeed, this statement testifies to the narrator's contradictory impulse to that of Mustapha who, as previously noted, has expressed concern about the European man's language in that it is emblematic of a source of threat to the African language and identity. Evident also in the above passage is the narrator's enhanced a sense of belonging to his native country. This idea can be said to have reflection in the statement "But I am from here", a telling statement which accounts for the narrator's quest for 
origin. Yet, as the following excerpt shows, the narrator feels that there is a fissure between himself and his native land and people:

I did not greet him [Mahjoub] and he did not turn to me but went on digging round the shoot. I remained standing, watching him. Then I lit a cigarette and held out the packet to him, but he refused with a shake of his head. I took my cares off to the trunk of a nearby date palm against which I rested my head. There is no room for me here. Why don't I pack up and go? Nothing astonishes these people. They take everything in their stride. They neither rejoice at a birth nor are saddened at a death. (Salih 1969: 130) [Emphasis mine]

Contrariwise to the previous statement wherein the narrator underlines that he is "from here", hence with belonging, this passage shows the narrator's perplexity which is evident in the gap that he feels exists between him and his "pays natal" along with its people. It is in this sense that the narrator's alienation within his country is foregrounded. Such a feeling can be said to have sprung from his dislocation abroad to the point that he cannot "[feel] his...bonds with the...native land" (Dash 1989: 332), as well as experience a "psychic re-memberment" (Dash 1989: 332), that is, to be a member again, through "the triumph over the estranging sea" (Dash 1989: 332). Indeed, the narrator's exile, estrangement and alienation contribute in dissociating himself from his own people whose attitudes are seen through the narrator's eyes as strange as they reveal no concern. In this manner, the narrator's affinity with Mustapha- towards whom the narrator's attitudes are ambivalent as they vacillate- is visible and relevant in that "the narrator shares with [Mustapha] not only common experience in the North but also a similar fate in the South" (Shaheen 1985: 161). Indeed, just like the narrator, Mustapha- who "was not a local man but a stranger who had come here five years ago" (Salih 1969: 2)experiences a sense of alienation within in much the same way as the narrator. It is in this light that, as will be discussed later, Mustapha and the narrator leave room for the interpretation of seeing them as doubles.

It is also worth making the point that Mustapha's attitudes towards the narrator are also ambivalent and show his splitting and/or "divided self". In this sense, the narrator is seen as the stranger and the uncanny. Yet, as John et, al. clearly state, Mustapha's "curiosity about the stranger involves both sympathy and antipathy- sympathy stemming from a shared sense of alienation, and antipathy deriving from a muted but real rivalry between them as native son and settler" (John and Taraweh 1986: 166). Indeed, Mustapha's ambivalent attitude is primarily informed by his alienation in his native land which is the result of his dislocation and displacement. In the main, Salih's characters enhance ambivalent attitudes not only towards people outside their country but also towards one another as has been extrapolated from the relationship between the narrator and Mustapha. 


\section{Mimic Man: The Black Man's "Going Western"}

If Kurtz is "the best known canonical example of the perils of going native" (Ashcroft, Griffiths and Tiffin 2013: 115), Mustapha Sa'eed, a distinctive postcolonial hero, is, along with Naipaul's Ralph Singh, probably a good case in point when it comes to "going western" and its nefarious consequences. Being the focal character around whom the main events revolve, Mustapha will be analyzed in such a way that shows his mimic acts, his "going western" which has led to his alienation, paranoid schizophrenia, and disillusionment, all of which feelings are as visible and as relevant as those Kurtz endured in Heart of Darkness. In fact, Season of Migration to the North is fraught with passages that account for Mustapha's mimicry. To exemplify, let's consider the following excerpt which reveals Mustapha's ability to master and appropriate the English language:

"I covered the first stage in two years and in the intermediate school I discovered other mysteries, amongst which was the English language. My brain continued on, biting and cutting like the teeth of a plough. Words and sentences formed themselves before me as though they were mathematical equations; algebra and geometry as though they were verses of poetry. I viewed the vast world in the geography lessons as though it were a chess board. The intermediate was the furthest stage of education one could reach in those days..." (Salih 1969: 22)

Through the white colonizers' eyes, notes Bhabha, "colonial mimicry is the desire for a reformed, recognizable Other, as a subject of difference that is almost the same, but not quite" (Bhabha 1994: 86). Basically, the need for mimic men springs from the white man's conviction that they will serve as a bridge between the Europeans and the rest of those natives they have under control. It is in this respect that one of the most striking paradoxes about colonialism comes to the fore and shows the slippages of colonial discourse: while there is a tendency to set apart Europeans from Africans based on the system of binarism, colonial mimicry effaces these borders. It is also in this line that mimicry results in ambivalent and hybrid identities which reify in no manner the Manichean portrayal as being fixed and pure, and it shows "a desire to sever the ties with 'self' in order to move towards 'other'" (Kumar 2011: 2). Yet, mimicry can turn out to be a source of threat to the white man, hence emerges a strategy of resistance in that it disturbs the authority of colonial discourse as Bhabha underlines and as the character of Mustapha testifies.

To pursue the same line of thinking, "raised 'through our English school"" (Bhabha 1994: 86), Mustapha masters the English language by virtue of his mind which he conceives of as his "sole weapon" as a "sharp knife inside [his] skull" (Salih 1969: 26). Certainly, it is this mastery of the English language, as part and parcel of his general knowledge, that has acted as a tool for exacting revenge upon the English women whom he seduces and whose bodies he appropriates and conquers. In this sense, Mustapha deploys the English language to cater for his needs of conquering the west sexually. This idea can be said to be illustrated in Mustapha's saying that the English "schools were started so as to teach us how to 
say 'Yes' in their language... Yes, my dear sirs, I came as an invader into your very homes: a drop of the poison which you have injected into the veins of history..." (Salih 1969: 95). This is revelatory of Mustapha's growing awareness of the role of colonial school, as well as his awareness of his mimicry and his resemblance which disrupts the authority of the colonizer in so far as, Bhabha states, "the look of surveillance returns as the displacing gaze of the disciplined, where the observer becomes the observed" "the look of surveillance returns as the displacing gaze of the disciplined, where the observer becomes the observed" (Bhabha 1994: 92). In this light, Mustapha's mimicry reverses the dialectics of power relationships as he becomes an observer above the white man.

Instances that testify to Mustapha's mastery of English, hence his mimicry and his resemblance to the white man, are many and various. What follows is one further example wherein Mamur, one of the ex-classmates of Mustapha, shows that latter's mastery of the white man's language, hence his assimilation:

[Mustapha] was the spoilt child of the English and we all envied him and expected he would achieve great things. We used to articulate English words as though they were Arabic and were unable to pronounce two consonants together without putting a vowel in between, whereas Mustafa Sa'eed would contort his mouth and thrust out his lips and the words would issue forth as though from the mouth of one whose mother tongue it was. This would fill us with annoyance and admiration at one and the same time. With a combination of admiration and spite we nicknamed him "the black Englishman". (Salih 1969: 52-53)

This passage further evinces Mustapha's mimicry of English which he masters and pronounces as if it were his mother language. In fact, as Mamur states, Mustapha is a distinguishable person when it comes to learning English to the point he is labeled by his classmates as "the black Englishman". This is a significant nickname which testifies to Mustapha's "going English" and his absorption of the English language. In this line of thought, if we admit the role of language as it offers a window to the other's culture, and a doorway into understanding his civilization, Mustapha is in no way able to absorb western civilization. It is at this juncture that Mustapha's "going western" is foregrounded as clearly seen in his fascination with the English language and culture. Yet, Mustapha's "going western", as previously hinted at, enhances in him a sense of paranoia as he wants to act as a god over the white women in such a way that reveals his self-deception. This idea is reminiscent of Conrad's Kurtz who, having gone native, has a burgeoning desire to control Africans and act as their god. In fact, his killing of Africans and placing their heads around the Inner Station shows his self-deception and his sense of paranoia and megalomania.

Although there is not much textual evidence that shows the narrator's "going western", it remains safe to regard him as no less striking example of mimic men in so far as he spends seven years in England studying English poetry. On this basis, the narrator can be said to be trapped between two cultures which make him lose his sense of identity and belonging. In fact, the narrator and Mustapha's loss of identity has led to their psychological disturbance, particularly upon their return to their native country. It is in this regard that the perils of "going western" are 
foregrounded. They are certainly a full embodiment of "the natives [who] feel perpetually trapped and shipwrecked in their native land for the destined wretchedness making them embrace borrowed culture, language, fashion and style only to experience ever-prevailing and ever-tormenting ambivalence which destabilizes their lives in entirety" (Kumar 2011:1). Torn between two experiences, the narrator and Mustapha endure a sense of alienation and dislocation to the point that they are strangers to each other, to their own villagers, and to themselves. Having been unable neither to reconnect with his homeland in Africa nor to bond himself with England through, for instance, establishing a library of English books, Mustapha feels completely detached as he has no belonging. Indeed, his sense of dislocation, psychological disturbance, and his loss of self-have resulted in his tragic death which he meets in the Nile in such a way that is evocative of Kurtz's tragic death in the Congo River.

Mustapha's vanishing intensifies, as previously pointed out, the narrator's impulse to identify with him, and to embark on a journey towards discovering Mustapha who is emblematic of his alter ego. This idea can be said to find expression in the moment when the latter enters the room of the former wherein he encounters his distorted face as the following excerpt shows:

I opened a second window and a third, but all that came in from outside was more darkness. I struck a match. The light exploded on my eyes and out of the darkness there emerged a frowning face with pursed lips that I knew but could not place. I moved towards it with hate in my heart. It was my adversary Mustafa Sa'eed. The face grew a neck, the neck two shoulders and a chest, then a trunk and two legs, and I found myself standing face to face with myself. This is not Mustafa Sa'eed - it's a picture of me frowning at my face from a mirror. (Salih 1969: 135)

Prior to and during this moment, the narrator expresses concern about Mustapha as a stranger, and he exhibits towards him a sense of aversion, hate, enmity, and a tendency of disassociation. Yet, given the ambivalent nature of identity, the narrator finds it hard to disassociate himself from Mustapha who "has... become part of the [narrator's] world, [and] a thought in [his] brain" (Salih 1969: 50). In fact, the narrator's obsession with Mustapha and his eagerness to know about him is in fact a search for his identity. The narrator's entrance into Mustapha's room shows his journey to discover his "self" which is reflected in the mirror, as shown in the above passage. As his mirror image, the narrator finds himself within the world of Mustapha with whom he identifies as his "alter ego reflecting the dark potential within the narrator himself" (John and Tataweh 1986: 165). In this sense, performed through Mustapha, the narrator's journey is a journey into the recesses of his soul. The narrator's identification with Mustapha as his alter ego is intensified, prior to the narrator's entrance in the room, in the moment of Mustapha's drowning in the Nile. This idea finds illustration in the narrator's asking: "Was it likely that what had happened to Mustafa Sa'eed could have happened to me? He had said that he was a lie, so was I also a lie? I too had lived with them..." (Salih 1969: 59). Ambivalent as it is, the narrator's attitude towards Mustapha rests on perplexity. Although the narrator strives hard to cut ties 
with Mustapha by deeming him a stranger, he still has a burgeoning desire to identify with him in such a way that testifies to their doubleness. In this sense, Mustapha remains the narrator's alter ego who absorbs western civilization, embraces modernity, and engages in a sexual conquest of the white women. All these things are emblematic of the narrator's dark self which he tries to hide as he claims maintaining his native traditions, pure identity, and his choice to avoid the white women. Yet, just like Mustapha, the narrator's being trapped between two cultures and experiences, his sense of dislocation, and his psychological disturbance have resulted in his following the path of Mustapha through throwing himself in the Nile. Indeed, as products of a shared traumatic experience, Mustapha and the narrator undergo the same fate.

\section{Conclusion}

This paper has offered a perspective on the issue of hybridity-which is unrelated to ambivalence and mimicry-that is represented, albeit in different ways, and occupies a central place in Season of Migration to the North. The crux argument of this paper lies in the idea that characters' development of hybrid identities stems mainly from cultural and colonial encounters and displacement in another space. Hybridity, as Bhabha shows, challenges the essentialist Manichean perception of identities based on drawing borders of difference between the self and the other. In the light of hybridity, these lines of demarcation are drawn into a Lacanian mirror-image wherein the other plays an important role in defining the self; hence the idea of the complementarity of identities. Yet, as the examination of Salih's characters has revealed, the hybrid and ambivalent identities have resulted in characters' conflicts with themselves and with their surroundings. Indeed, characters' ambivalence enhances in them a sense of alienation, exile, and dislocation, all of which, as the case of Mustapha evidences, have led to the characters' loss of self, hence their tragic ends.

\section{References}

Ashcroft B, Griffiths G, Tiffin H (Eds.) (2013) Postcolonial Studies: The Key Concepts $\left(3^{\text {rd }} \mathrm{Ed}\right.$.). New York: Routledge.

Bhabha KH (1994) The Location of Culture. London: Routledge.

Dash M (1989) "In Search of the Lost Body: Redefining the Subject in Caribbean Literature". Kunapipi 11(1): Article 5. Retrieved from https://bit.ly/2QRI7qm.

Geesey P (1997) "Cultural Hybridity and Contamination in Tayeb Salih's Mawsim al-hijra ila al-Shamal". Season of Migration to the North 28(3): 128-140.

John J, Taraweh Y (1986) "Quest for Identity: The I-Thou Imbroglio in Tayeb Salih's: Season of Migration to the North". Arab Studies Quarterly 8(2): 161-177.

Kumar S (2011) "Bhabha's Notion of Mimicry and Ambivalence in V.S Naipaul's A Bend in the River". Journal of Arts, Science \& Commerce II(4, Oct.).

Loomba A (1998) Colonialism/ Postcolonialism. London and New York: Routledge.

Makdisi SS (1992) "The Empire Renarrated: Season of Migration to the North and the Reinvention of the Present". Critical Inquiry 18(4): 804-820. 
Shaheen M (1985) "Tayeb Salih and Conrad". Comparative Literature Studies 22(1): 156171.

Salih T (1969) Season of Migration to the North. London: Heinemann.

Stampfl T (2009) "(Im)possible Encounters, Possible (mis)understandings between the West and its other: The Case of the Maghreb". Availabe at: https://bit.ly/2AgpeDe. 